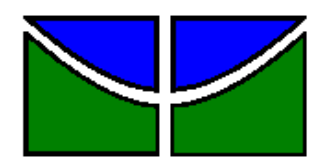

UNIVERSIDADE DE BRASÍLIA - UNB

FACULDADE DE ECONOMIA, ADMINISTRAÇÃO, CONTABILIDADE E CIÊNCIA DA INFORMAÇÃO E DOCUMENTAÇÃO (FACE)

CURSO DE ESPECIALIZAÇÃO EM GESTÃO JUDICIÁRIA

EDSON SANTOS DA SILVA

\title{
USABILIDADE DO SISTEMA DE AUTOMAÇÃO DE GABINETES DO SUPERIOR TRIBUNAL DE JUSTIÇA
}




\title{
USABILIDADE DO SISTEMA DE AUTOMAÇÃO DE GABINETES DO SUPERIOR TRIBUNAL DE JUSTIÇA
}

\author{
Monografia apresentada ao Departamento de \\ Administração da Faculdade de Economia, \\ Administração, Contabilidade e Ciência da \\ Informação e Documentação (FACE) da \\ Universidade de Brasília como requisito parcial à \\ obtenção do grau de Especialista em Gestão \\ Judiciária.
}

Orientadora: Prof ${ }^{\mathrm{a}} \mathrm{Dr}^{\mathrm{a}}$ Sueli Angélica do Amaral 


\section{AGRADECIMENTOS}

À minha orientadora Profa. Dra. Sueli Angélica do Amaral. Pela compreensão; pela paciência; pela dedicação; pela disponibilidade; pela firmeza aliada à serenidade; pela sabedoria; e pelo conhecimento transmitido.

MUITO OBRIGADO. 


\section{RELAÇÃO DE ABREVIATURAS E SIGLAS}

IEC - International Electrotechnical Comission

ISO - International Organization for Standardization

SAG - Sistema de Automação de Gabinetes

STI - Secretaria da Tecnologia da Informação

STJ - Superior Tribunal de Justiça

RISTJ - Regimento Interno do Superior Tribunal de Justiça

TI - Tecnologia da Informação 


\section{RELAÇÃO DE FIGURAS}

Figura 1 - Fluxo da informação nos sistemas de informação ......................................... 9

Figura 2 - Tela de login do Sistema Justiça.................................................................. 13

Figura 3 - Tela principal do Sistema de Automação de Gabinetes...................................... 14

Figura 4 - Estruturação dos cargos de ministro do STJ.................................................. 15

Figura 5 - Estruturação funcional de julgamento do STJ.............................................. 15

\section{RELAÇÃO DE QUADROS}

Quadro 1 - Classificação dos sistemas de informação ....................................11

\section{RELAÇÃO DE TABELAS}

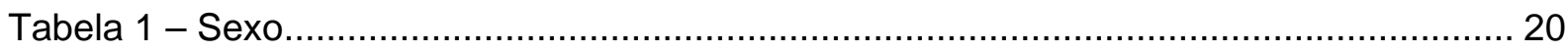

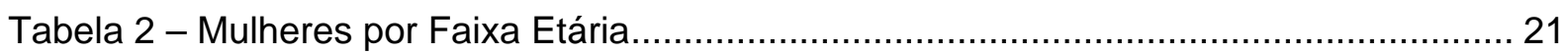

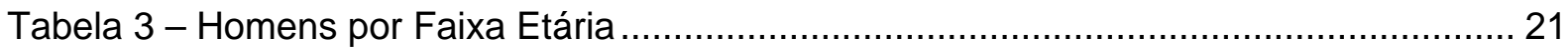

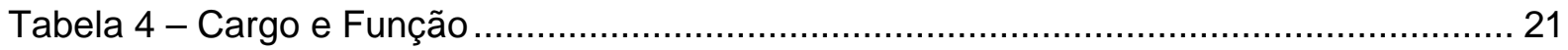

Tabela 5 - Freqüência de uso do sistema.............................................................. 22

Tabela 6 - Ambiente do de formatação de textos do Editor de Documentos ...................... 22

Tabela 7 - Visualização das informações processuais ..................................................... 22 


\section{SUMÁRIO}

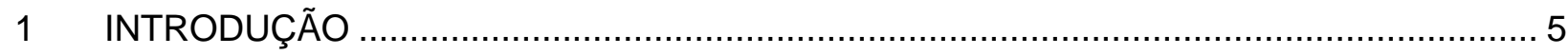

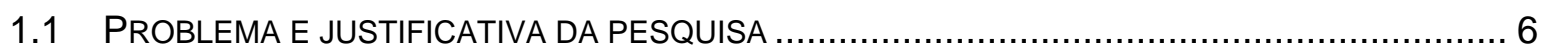

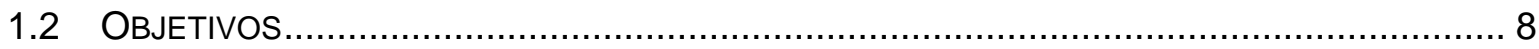

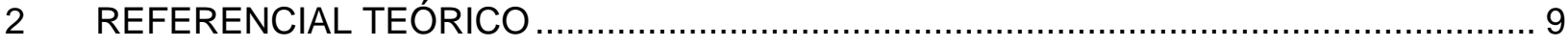

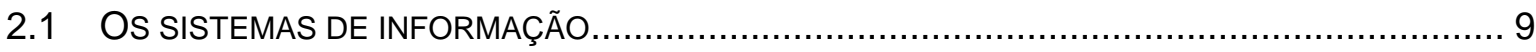

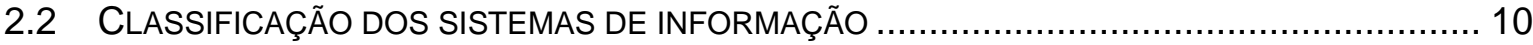

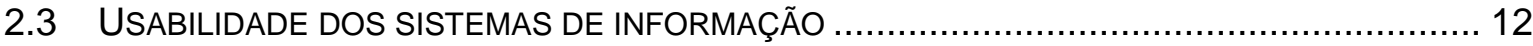

2.4 O SISTEMA DE AUTOMAÇÃO DE GABINETES DOS MINISTROS DO STJ …...................... 12

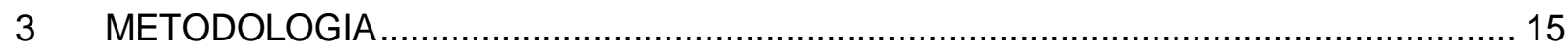

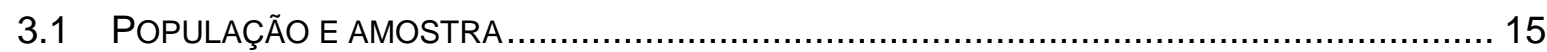

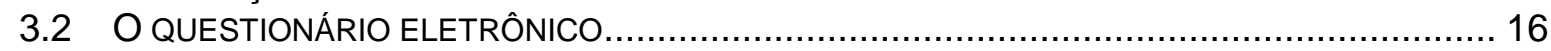

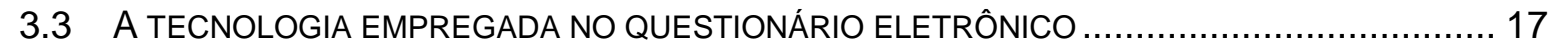

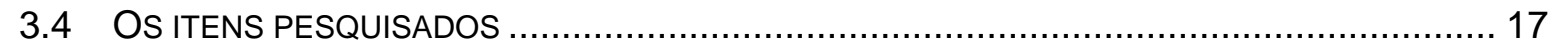

4 AVALIAÇÃO DO INSTRUMENTO DE COLETA DE DADOS …............................... 19

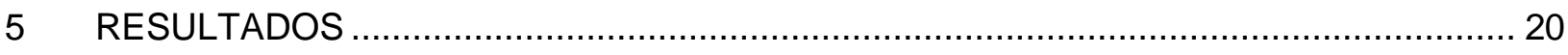

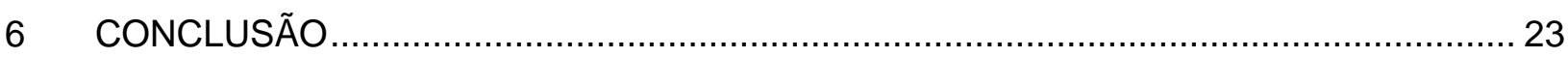

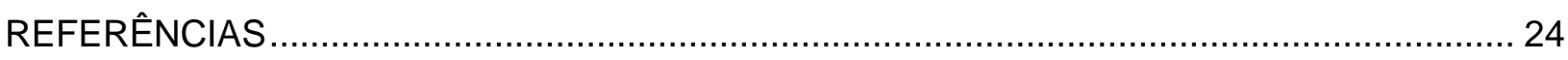

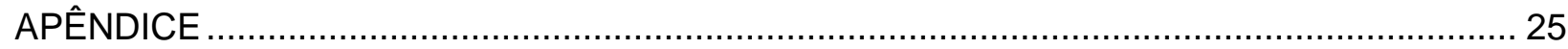




\section{INTRODUÇÃO}

A informação como fator de apoio à decisão representa redução de incertezas, além de minimização dos riscos da ocorrência de ações prejudiciais ou onerosas à organização. Logo, a informação precisa fazer parte da estratégia de qualquer organização, pois representa um fator decisivo para alcançar os objetivos pretendidos.

A eficácia organizacional depende de processos decisórios e operacionais alimentados com informações de qualidade, num contexto de administração adequada e racional dos recursos computacionais.

Beal (2004, p.22) afirma que "o desempenho de uma organização está condicionado à qualidade das ligações do fluxo informacional existente para proporcionar o intercâmbio de idéias e informações".

Nesse contexto, alguns elementos fundamentais na dimensão organizacional podem ser evidenciados, quais sejam: dados, processos, fluxo informacional, recursos computacionais e informação. A conjugação de todos esses elementos requer uma abordagem sistêmica, mais precisamente, a utilização da arquitetura da tecnologia da informação (TI) para a idealização de sistemas de informação de apoio à organização.

Para melhor compreensão da terminologia de arquitetura de $\mathrm{TI}$, apresenta-se uma comparação, segundo a qual "a arquitetura de TI é semelhante à arquitetura de uma casa. A arquitetura de uma casa, mostrada por plantas, descreve como a casa deve ser construída, incluindo a integração dos componentes da casa, como o sistema hidráulico, o sistema elétrico e assim por diante" (TURBAN; RAINER; POTTER, 2005, p.39).

Santiago Júnior (2004, p.53) esclarece que "a tecnologia da informação (TI) é o centro nervoso das empresas, por ser um fator estratégico de competitividade e sobrevivência das organizações". O autor ressalta a importância da TI para dar suporte à gestão do conhecimento das organizações, mas alerta que "muitas vezes, no entanto, tem sido subestimado e até mesmo ignorado pela maioria das empresas. Seu grande objetivo em uma organização é identificar, encontrar e/ou desenvolver e implementar tecnologias e sistemas de informação que apóiem a comunicação empresarial".

Segundo os Ferreira e Nunes (2008, p.2), o acesso à informação de qualidade é essencial para a eficácia de uma organização, pois estas não funcionam sem informação; elas precisam de sistemas capazes de tratar suas informações de maneira sistemática e automatizada. 
O sistema de informação representa, portanto, o produto pretendido pela TI para o atendimento da demanda organizacional por mecanismos de processamento e controle de suas atividades. O'Brien (2006, p.10) apresenta uma definição simples de sistema de informação (SI) como "um conjunto organizado de pessoas, hardware, software, redes de comunicação e recursos de dados que coleta, transforma e dissemina informações em uma organização".

Atualmente, os computadores são usados por um grande número de usuários, notadamente motivados pela redução do preço de aquisição e da popularização do produto com o lançamento dos computadores pessoais. Esta tendência de popularização dos equipamentos de informática conduziu à necessidade de interfaces mais voltadas para os usuários, de forma a reduzir o tempo de aprendizado das tarefas.

Assim, tornou-se comum a referência ao termo "usabilidade" para avaliar a qualidade dos equipamentos (hardware) e dos aplicativos (software), tendo relação direta com a facilidade de uso, eficiência, tratamento adequado de erros e satisfação dos usuários.

Este trabalho propõe um instrumento de avaliação da usabilidade do Sistema de Automação de Gabinetes (SAG) do Superior Tribunal de Justiça (STJ) sob o ponto de vista do usuário, tratando-se, portanto, de um instrumento de coleta de dados sobre a satisfação desses usuários, que poderá servir à Secretaria de Tecnologia da Informação (STI) do Tribunal como uma base alternativa em busca da melhoria do desempenho do principal sistema de informação do STJ.

\subsection{Problema e justificativa da pesquisa}

O Superior Tribunal de Justiça apresenta em seu contexto corporativo, em regra, como em qualquer organização, complexos e minuciosos fluxos de informações que demandam uma abordagem sistêmica para o alcance racional e efetivo de seu objetivo maior que é a prestação jurisdicional demandada pela sociedade.

Assim, congregando atividade meio e atividade fim, o Tribunal soluciona as lides e atende as requisições que lhes são submetidas pelos cidadãos, empresas, governo e suas próprias unidades e servidores, na qualidade de clientes, mediante uma percepção particularizada do serviço prestado, se os julgamentos são concluídos com celeridade e efetividade, como pressuposto de uma justa solução dos conflitos (atividade fim) e o grau de satisfação do público interno e externo com a qualidade do serviço administrativo e gerencial prestado (atividade meio). 
$\mathrm{Na}$ estrutura organizacional do Superior Tribunal de Justiça há uma unidade denominada Secretaria de Tecnologia da Informação (STI), encarregada de disponibilizar e gerenciar sistemas de informação automatizados para as várias unidades do Tribunal. Dentre essas unidades, destacam-se os gabinetes dos ministros que prestam aos magistrados serviços administrativos e de assessoramento jurídico, tendo sua competência, composição e estruturação previstos no Regimento Interno do STJ (RISTJ).

Os gabinetes são unidades administrativas de funcionalidade complexa, pois desenvolvem suas atividades envolvendo várias áreas, principalmente a jurídica e a administrativa, no que diz respeito à gestão de pessoas e dos processos judiciais. Necessitam, portanto, de sistemas de informação automatizados que apóiem satisfatoriamente a operacionalização dessas atividades.

A STI disponibiliza para os gabinetes dos ministros um sistema de informação, denominado Sistema de Automação de Gabinetes (SAG); que foi projetado para o controle do andamento dos processos judiciais, edição de decisões, preparação das pautas de julgamentos e envio eletrônico de documentos para a publicação.

Neste ponto, destaca-se que o autor deste trabalho já foi contemplado por duas vezes com premiação no concurso denominado "Melhores Idéias", promovido pelo STJ na área de tecnologia com implementação motivada pela deficiência do SAG em atender demandas específicas de automatização de rotinas.

Ressalta-se que os sistemas desenvolvidos para completar o uso do SAG foram inicialmente planejados para atenderem o uso pessoal do autor, entretanto, outros gabinetes tomaram conhecimento da existência dessas implementações, o que levou os chefes dessas unidades a requisitarem formalmente, inclusive, em alguns casos, por pedido feito pessoalmente pelo ministro para a instalação desses sistemas nos respectivos gabinetes.

Este fato despertou o interesse pela necessidade de se investigar porque os usuários buscam alternativas para complementar o uso do SAG.

O SAG é usado pelos servidores dos gabinetes e, também, pelos ministros, sendo que todas as atividades desenvolvidas nessas unidades são efetivamente realizadas por intermédio deste sistema de informação. Todas as decisões e votos dos julgamentos têm que ser preparados e publicados por meio desse sistema.

Percebe-se, portanto, que o uso desta ferramenta de automação é literalmente indispensável para a atividade dos gabinetes dos ministros e, conseqüentemente, de todo o Tribunal, pois essas unidades desenvolvem as denominadas atividades fim da organização. 
Apesar da importância desse sistema de informação para o apoio das atividades dos gabinetes dos ministros, não há um estudo específico sobre ele e o seu uso no Tribunal, notadamente quanto a satisfação dos servidores lotados nos gabinetes com relação à usabilidade do sistema.

Assim, o problema de pesquisa será:

como avaliar a usabilidade do Sistema de Automação de Gabinetes do Superior Tribunal de Justiça, sob o ponto de vista dos usuários?

\subsection{Objetivos}

O objetivo geral do trabalho será propor e testar um questionário eletrônico para avaliar a satisfação dos servidores lotados nos gabinetes dos ministros do Superior Tribunal de Justiça quanto à usabilidade do Sistema de Automação de Gabinetes.

Para o alcance desse objetivo, relacionam-se os seguintes objetivos específicos:

a) Classificar as questões do questionário eletrônico por categoria a partir de cada módulo (ou subsistema) integrante do Sistema de Automação de Gabinetes;

b) Aplicar o questionário prévio em um dos gabinetes de ministro do STJ para testá-lo como instrumento de coleta para avaliação da satisfação do usuário;

c) Avaliar os resultados obtidos para depuração das questões quanto à coerência e relevância para o estudo de satisfação dos demais usuários do SAG no Tribunal; 


\section{REFERENCIAL TEÓRICO}

\subsection{Os sistemas de informação}

Segundo Laudon e Laudon (2001, p.4), os sistemas de informação processam informações sobre pessoas, lugares e coisas de interesse dentro da organização ou do ambiente que o cercam.

Laudon e Laudon (2001, p.5) definem a informação como "o resultado dos dados que foram moldados de uma forma que é significativa e útil para os seres humanos, e os dados dizem respeito a fatos brutos, que representam os eventos que acontecem em organizações ou ambiente físico antes de serem organizados e arrumados de uma forma que as pessoas possam entender e usar".

A Figura 1 representa o típico tratamento dos dados pelos sistemas de informação no contexto organizacional. Bio (1991, p.28) esclarece que os dados de entrada são coletados e transportados até o ponto de processamento por meios manuais, mecânicos ou eletrônicos para uma série de operações necessárias ao registro e conversão em informação de saída desejável envolvendo, em síntese, dois aspectos: classificação/ordenação dos dados e cálculos.

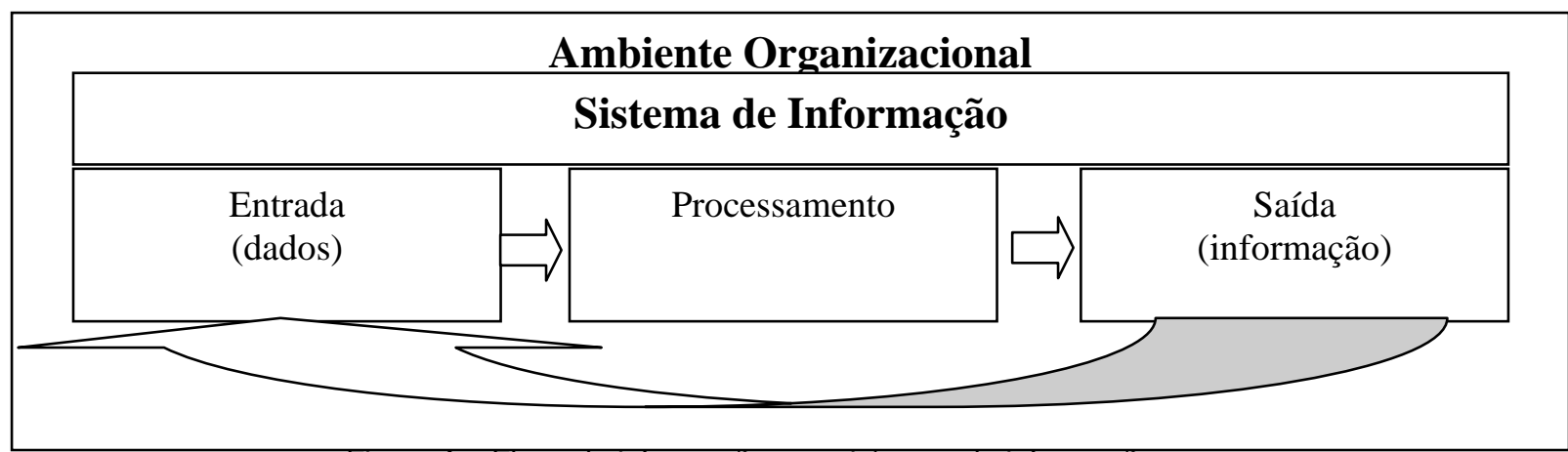

FIgura 1 - Fluxo da Informação nos sistemas de Intormação

Fonte: BIO (1991, p. 29)

Segundo Albertão (2001, p.75), "os elementos ou componentes do sistema coletam (entrada), manipulam ou armazenam (processamento) e disseminam (saída) dados como um mecanismo de fonte de informações utilizadas pelos usuários para a tomada de decisões".

De acordo com Turban, Rainer e Potter (2005, p.40): 
sistema de informação que utiliza a tecnologia de um computador para realizar alguma ou todas as suas tarefas planejadas.

Para os autores (TURBAN; RAINER; POTTER, 2005, p.46), "a coleção de programas aplicativos projetados para dar suporte a um único departamento é considerada um sistema de informação departamental". Pela definição, por exemplo, a coleção de programas aplicativos na área de recursos humanos é chamada de sistema de informação de recursos humanos. Em outras palavras, sistema de informação pode ser definido como uma coleção de programas aplicativos de suporte a tarefas específicas.

\subsection{Classificação dos sistemas de informação}

O estudo da classificação dos sistemas de informação justifica-se pela otimização da adequação funcional desses sistemas, orientados para o efetivo atendimento das necessidades dos usuários. Imprescindível, portanto, um estudo criterioso das atividades e dos fluxos de informações relativos aos grupos e indivíduos destinatários desse produto informacional.

Beal (2004, p.36) esclarece que "as necessidades e requisitos de informação podem variar substancialmente de um usuário para outro, e é comum que os usuários da informação não sejam capazes de identificar ou expressar suas necessidades claramente". Assim, é necessário conhecer a informação requerida e sua destinação, pois esta mesma informação poderá gerar diferentes conceitos de organização e apresentação, sendo necessário, também, conhecer os usuários da informação e suas necessidades relativas ao fluxo informacional.

Segundo os autores Turban, Rainer e Potter (2005, p.49), os sistemas de informação são classificados em grupos que compartilham características semelhantes, sendo duas as classificações comumente conhecidas: classificação por amplitude de suporte e classificação por níveis organizacionais. Os sistemas de informação por amplitude de suporte subdividem-se em funcionais (departamentais) corporativos e interorganizacionais, e os classificados por níveis organizacionais em administrativo, operacional, gerencial e estratégico.

O Quadro 1 sintetiza a classificação dos sistemas de informação de acordo com a classificação dos autores Turban, Rainer e Potter (2005). 


\begin{tabular}{|l|l|}
\hline \multicolumn{2}{|c|}{ Classificação dos sistemas de informação } \\
\hline $\begin{array}{l}\text { Classificação por amplitude de } \\
\text { suporte }\end{array}$ & Classificação por níveis organizacionais \\
\hline - $\begin{array}{l}\text { Funcionais (departamentais); } \\
\text { - Corporativos; }\end{array}$ & - Nível administrativo; \\
- Interorganizacionais. & - Nível operacional; \\
& - Nível estratégico. \\
\hline
\end{tabular}

Quadro 1 - Classificação dos sistemas de informação Fonte: Elaborado pelo próprio autor

Os sistemas de informação funcionais (ou departamentais) são organizados em torno de departamentos tradicionais em uma organização, como de manufatura, contabilidade, finanças, marketing e recursos humanos (TURBAN; RAINER; POTTER, 2005, p.47).

Segundo Turban, Rainer e Potter (2005, p.47), os sistemas de informação corporativos compreendem

sistemas projetados para atenderem a diversos departamentos ou à corporação inteira e permitem que pessoas se comuniquem entre si e acessem informações por toda a organização. Esses sistemas juntamente com os sistemas de informação funcionais, compreendem o sistema de informação corporativo

A conexão entre as organizações e o gerenciamento da cadeia de fornecimento é feita por meio dos sistemas de informação interorganizacionais, que descreve o fluxo de materiais, informações, dinheiro e serviços desde os fornecedores, fábricas, armazéns até chegar ao consumidor final (TURBAN; RAINER; POTTER, 2005, p.47).

Os sistemas de informação do nível administrativo são sistemas destinados a usuários que usam, manipulam e disseminam informações. Esses usuários dão suporte a gerentes em todos os níveis da empresa (TURBAN; RAINER; POTTER, 2005, p.48).

Os sistemas do nível operacional são considerados críticos para o sucesso de qualquer empresa, pois dão suporte às operações básicas, como compra de materiais, cobrança de clientes, preparação de folha de pagamento, remessa de bens aos clientes, emissão de extratos financeiros etc (TURBAN; RAINER; POTTER, 2005, p.49);

Conhecidos comumente apenas como SIG, os sistemas de informação do nível gerencial, estes

são projetados para resumir dados e preparar relatórios para as áreas funcionais, como contabilidade e marketing, para facilitar a tomada de decisões. Auxiliam a área gerencial fornecendo resumos estatísticos, análise comparativa, detecção inicial dos problemas e projeções em geral (TURBAN; RAINER; POTTER, p.49) 
Os sistemas do nível estratégico "utilizam ferramentas de análise e comparação complexas, permitindo o monitoramento do desempenho organizacional, além das atividades dos concorrentes, destacando problemas, identificando oportunidades e prevendo tendências" (LAUDON; LAUDON, 2001, p.328).

\subsection{Usabilidade dos sistemas de informação}

O requisito da usabilidade do sistema de informação diz respeito à facilidade de uso ou de aprendizagem. Bio (1991, p.26) refere-se à usabilidade como a capacidade do sistema de informação de atender as expectativas do usuário de forma a atender satisfatoriamente suas necessidades operacionais ou de tomadas de decisões.

A norma ISO/IEC 9126-1, que normatiza a qualidade de software, define o termo usabilidade como "um conjunto de atributos de software relacionado ao esforço necessário para seu uso e para o julgamento individual de tal uso por determinado conjunto de usuários" (ISO, 2001).

Cybis et al (2007, p.15) esclarecem que usabilidade

não é uma qualidade intrínseca de um sistema, mas depende de um acordo entre as características de sua interface e as características de seus usuários ao buscarem determinados objetivos em determinadas situações de uso

Ferreira e Nunes (2008, p.20) afirmam que a usabilidade se determina pela facilidade de manuseio, capacidade de aprendizado rápido, dificuldade de esquecimento, ausência de erros operacionais, satisfação do usuário e eficiência na execução das tarefas a que o sistema de informação se propõe.

Os autores registram que "se bem projetada, a interface, pode se tornar uma fonte de motivação, e, ainda, dependendo de suas características, uma grande ferramenta para o usuário" (FERREIRA; NUNES, 2008, p.3)

\subsection{O Sistema de Automação de Gabinetes dos Ministros do STJ}

O Sistema de Automação de Gabinetes é parte integrante do Sistema Integrado da Atividade Judiciária, sendo este comumente conhecido apenas como Sistema Justiça. Trata-se do principal e mais utilizado aplicativo nos gabinetes dos ministros do STJ. 
É com ele que cada gabinete desempenha a maioria de suas atividades, sejam elas no âmbito da secretaria do gabinete (controle processual) ou na assessoria (análise e elaboração dos documentos).

O acesso ao Sistema Justiça é feito apenas para usuários cadastrados na STI do Tribunal que recebem um nome de rede (nickname) e uma senha (password) que deverão ser informados em uma tela inicial de acesso, conforme ilustrado na figura a seguir.

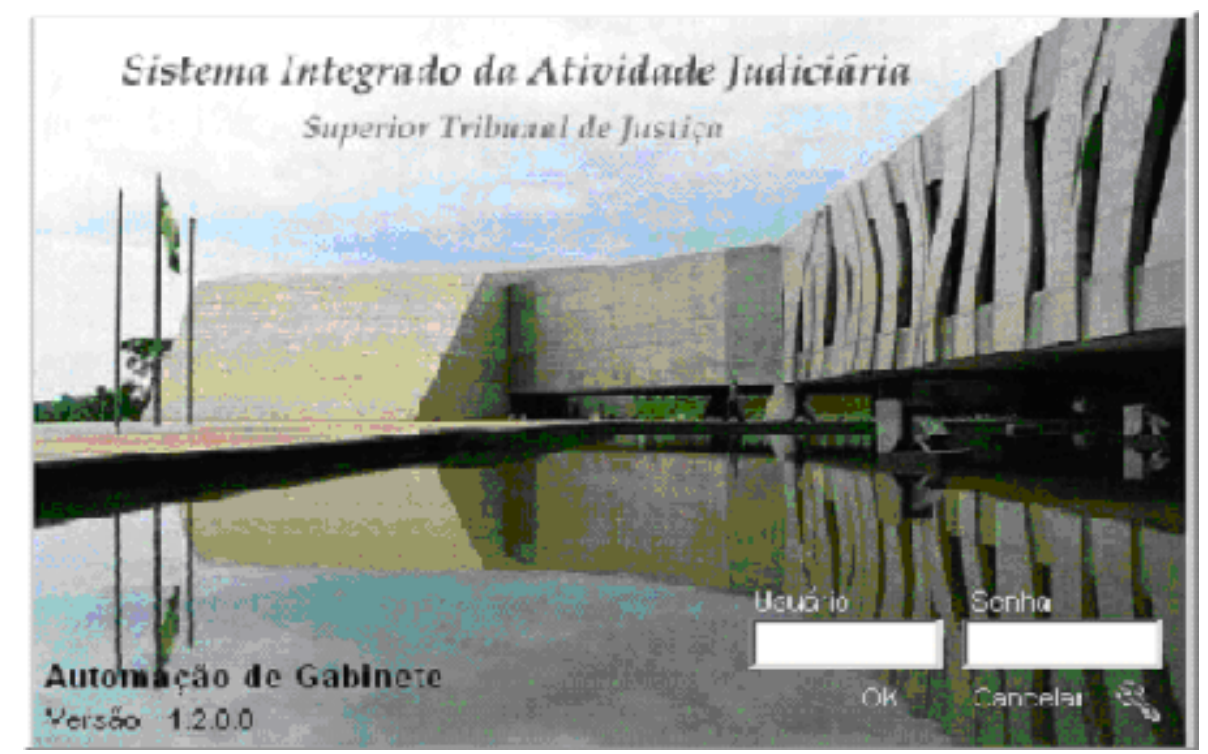

Figura 2 - Tela de login do Sistema Justiça Fonte: Sistema Justiça do STJ

Após a autenticação requerida na tela login, o usuário cadastrado, acessará a tela principal do SAG, conforme a figura a seguir: 


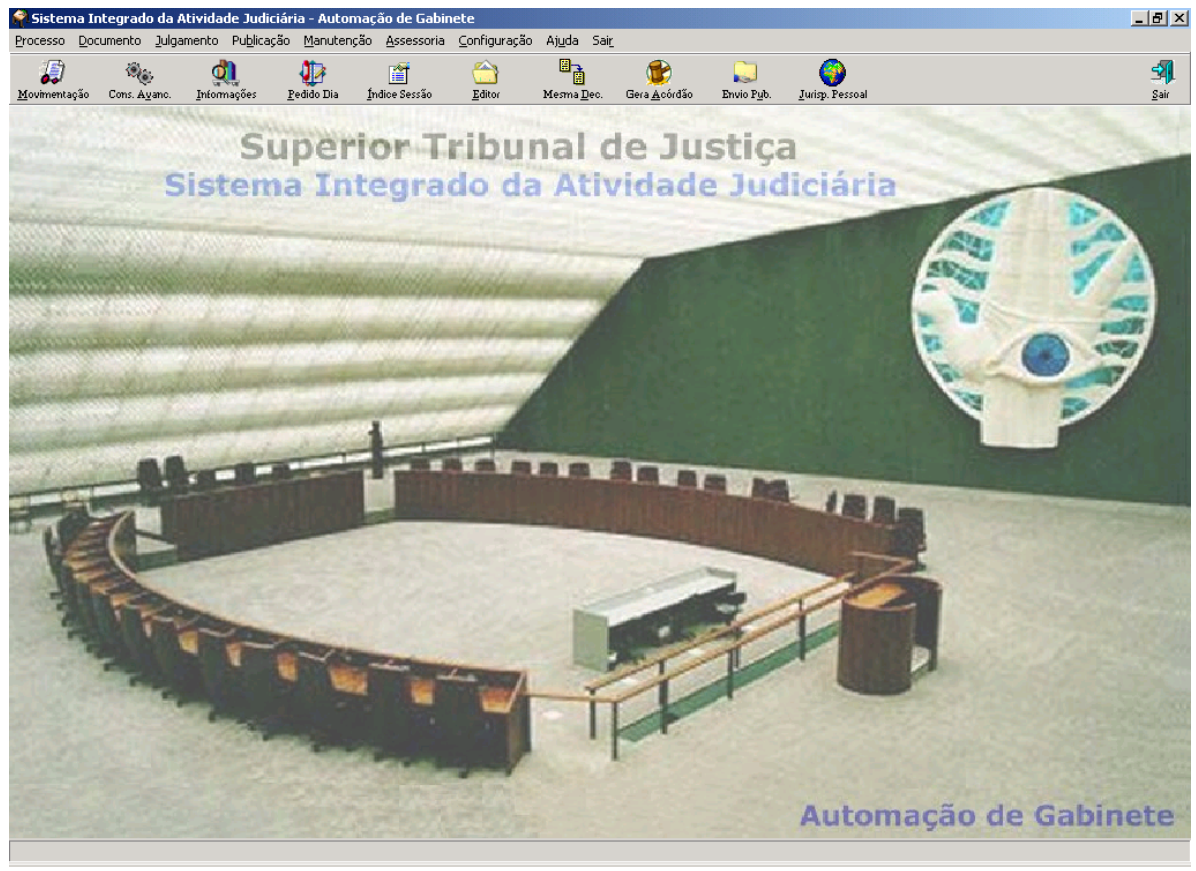

Figura 3 - Tela principal do Sistema de Automação de Gabinetes Fonte: Sistema Justiça do STJ

A partir da tela principal do SAG, o usuário poderá acessar as rotinas principais que são:

- Editor de Documentos;

- Envio Eletrônico para Publicação;

- Índice de Sessão de Julgamento;

- Informações Processuais. 


\section{METODOLOGIA}

A abordagem adotada para a pesquisa é de natureza quantitativa e qualitativa, mas predominantemente quantitativa.

\subsection{População e amostra}

O Superior Tribunal de Justiça "com sede na Capital Federal e jurisdição em todo o território nacional, compõe-se de trinta e três ministros" (REGIMENTO INTERNO DO STJ, art. $\left.1^{\circ}, 2008\right)$. O Tribunal é composto, portanto, por 33 gabinetes, respectivamente para o ministro Presidente, ministro Vice-Presidente, ministro Corregedor do Conselho Nacional de Justiça, ministro Coordernador-Geral da Justiça Federal e os demais 30 ministros que compõem as Seções especializadas da Corte.

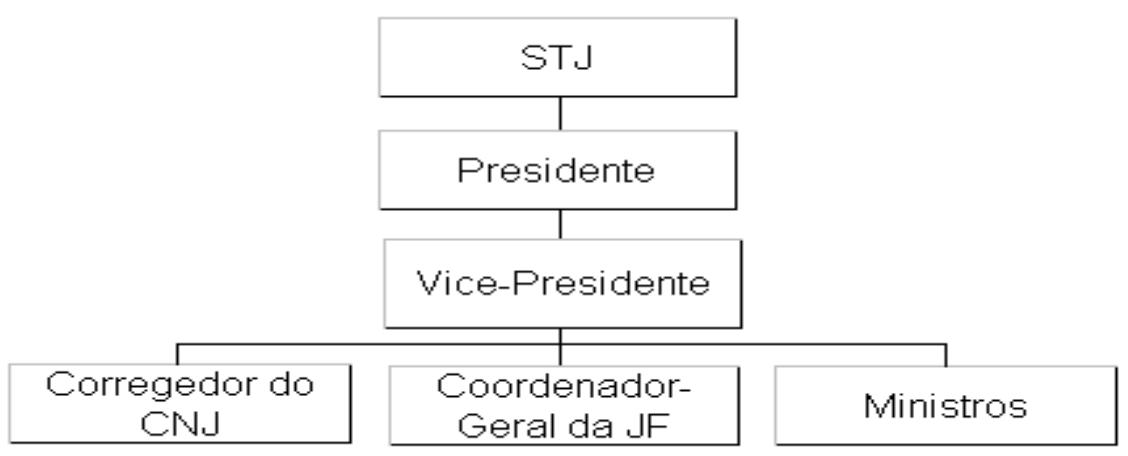

Figura 4 - Estruturação dos cargos de ministro do STJ Fonte: Elaborado pelo próprio autor

A estruturação dos órgãos julgadores do Tribunal definida no RISTJ pode ser ilustrada conforme a figura a seguir:

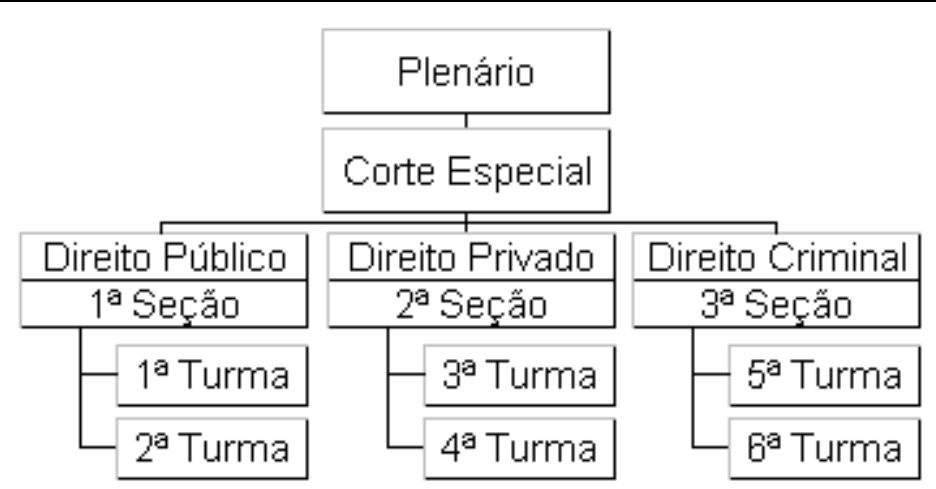

Figura 5 - Estruturação funcional de julgamento do STJ Fonte: Elaborado pelo próprio autor 
O SAG foi projetado e desenvolvido para atender as necessidades de apoio informatizado dos gabinetes dos ministros do STJ. O estudo diz respeito a uma pesquisa descritiva da usabilidade do SAG, sob o ponto de vista dos usuários dos gabinetes, restringindo-se, portanto, apenas a estas unidades.

A população é representada pelas seis turmas (figura 5) especializadas de julgamento que são compostas por cinco ministros, e, por conseguinte, somando trinta gabinetes de ministros, além dos gabinetes dos ministros Presidente, Vice-Presidente e Coordenador-Geral da Justiça Federal, totalizando, portanto, 33 gabinetes em todo o tribunal. O ministro Corregedor do Conselho Nacional de Justiça não tem gabinete do STJ. Portanto, cada gabinete de ministro conta com 21 servidores lotados, a população usuária é representada por 693 servidores $(21 \times 33)$.

A pesquisa não envolveu todos os 33 gabinetes de ministro, devido à impossibilidade de sua realização, uma vez que o tempo exigido para a execução de uma pesquisa dessa dimensão seria incompatível com o tempo para elaboração de uma monografia de conclusão de curso de especialização. Entretanto, o presente estudo poderá servir como um projeto piloto para testar a metodologia a ser empregada na realização a posteriori da análise da usabilidade do SAG.

A pesquisa foi desenvolvida selecionando-se um gabinete de ministro integrante $3^{\mathrm{a}}$ Turma. A amostra estatística é representada por 13 servidores desse gabinete, selecionados de acordo com suas atribuições funcionais relacionadas com a possibilidade de uso do SAG.

\subsection{O questionário eletrônico}

O primeiro contato com as unidades para a coleta dos dados iniciou-se por meio de contato telefônico com os Chefes de Gabinete de cada unidade para apresentação e esclarecimento do objetivo do trabalho.

Inicialmente, um questionário de teste foi enviado para alguns servidores para validação do instrumento. Nesse primeiro trabalho de coleta, foram preenchidos oito questionários.

Posteriormente, o endereço eletrônico do questionário eletrônico definitivo foi enviado via e-mail a todos os servidores lotados nos respectivos gabinetes. 
O questionário foi elaborado buscando-se evidenciar a facilidade de utilização do SAG sob o enfoque do usuário, além das três subcaracterísticas da qualidade, segundo a norma ISO/IE 9126-1: intelegibilidade (é fácil entender?), apreensibilidade (é fácil aprender?) e operacionalidade (é fácil operar?).

Além dessas subcaracterísticas, as perguntas foram direcionadas, objetivando evidenciar o uso e a necessidade de rotinas de trabalho não implementadas no Sistema de Automação de Gabinetes.

\subsection{A tecnologia empregada no questionário eletrônico}

O questionário foi hospedado em um servidor de Internet no endereço eletrônico http://www.ruthimoveis.com/stj/quest.asp e foi desenvolvido com a tecnologia Active Server Page (ASP), que permite trabalhar com o documento de perguntas armazenado em um servidor da internet com conteúdo dinâmico, ou seja, todo o código é gerado no servidor remoto e o usuário visualiza apenas a página que foi formatada remotamente.

A vantagem da tecnologia ASP é que os dados enviados pelos respondentes dos questionários podem ser automaticamente tabulados e calculados no próprio site.

A outra tecnologia empregada foi a linguagem de script de páginas de Internet denominada JavaScript, que permitiu a validação dos itens do questionário eletrônico antes do envio definitivo para o servidor. Por exemplo, o item 1 do questionário trata da freqüência de uso do subsistema "Editor de Documentos" ("diariamente", "semanalmente", "mensalmente", "raramente" ou "não utilizo"), assim se a opção for "não utilizo" os outros itens relacionados serão marcados, automaticamente, como "não se aplica" e a pergunta será protegida para alteração.

\subsection{Os itens pesquisados}

O questionário inicia com o quadro de dados complementares usados para identificar a unidade pesquisada e levantar características pessoais e profissionais do perfil de servidor.

No quadro seguinte do questionário, o usuário deverá selecionar a freqüência de utilização de cada um dos subsistemas integrantes do SAG: 
- Editor de Documentos;

- Envio Eletrônico para Publicação;

- Índice de Sessão de Julgamento;

- Informações Processuais.

No preenchimento deste quadro de freqüência de uso dos subsistemas citados, o usuário pode escolher uma das seguintes opções: "diariamente", "semanalmente", "mensalmente", "raramente" e "não utilizo".

Neste ponto, destaca-se que para facilitar o preenchimento, se o usuário escolher a opção "não utilizo", o questionário automaticamente protegerá as perguntas subseqüentes que tenham relação com subsistema indicado como não utilizado, marcando a pergunta protegida com a opção "não se aplica".

O questionário eletrônico foi desenvolvido com questões fechadas para coletar e armazenar os dados em banco de dados remoto.

Uma das questões poderá ser respondida pelo usuário de forma aberta para registrar sua sugestão ou comentário sobre o SAG. As demais questões são fechadas com uma escala definida de acordo com o contexto da pergunta (apêndice 1). 


\section{AVALIAÇÃO DO INSTRUMENTO DE COLETA DE DADOS}

Quanto ao instrumento de coleta, por meio de uma breve entrevista, 3 usuários registraram que consideraram o layout do instrumento de coleta, a organização e a compreensão das questões como satisfatórios.

Outro usuário participante da pesquisa esclareceu que considera o preenchimento do questionário por meio eletrônico uma forma de tornar o processo mais ágil.

O tempo médio necessário para o preenchimento de todas as questões do questionário eletrônico é de aproximadamente 4 minutos.

O cálculo para medição foi obtido pela média do tempo de preenchimento por dois usuários que responderam o questionário em 3 minutos e 40 segundos e 4 minutos e 20 segundos, respectivamente. Logo, o tempo médio pode ser obtido pelo seguinte cálculo:

$[(3 \min \times 60+40 \mathrm{seg}+4 \min \times 60+20 \mathrm{seg}) \div 2] \div 60=4$ minutos

De forma geral, constatou-se que os usuários fizeram uma avaliação positiva do instrumento de coleta de dados, não sendo necessário, portanto, alterar a sua estrutura ou reformular suas questões. 


\section{RESULTADOS}

A pesquisa foi elaborada com o envio de 21 questionários, e destes, 13 questionários foram respondidos, correspondendo, portanto, a aproximadamente $62 \%$ do total de questionários enviados.

A análise dos resultados tratada neste tópico objetiva apenas demonstrar que o instrumento de coleta de dados proposto, efetivamente, permite a combinação e o cruzamento dos dados obtidos, não se pretende, portanto, apresentar qualquer conclusão sobre o mérito das respostas apresentadas sobre as características de usabilidade do sistema de informação estudado.

Como será demonstrado, os dados coletados podem ser combinados de várias maneiras, de forma isolada ou cruzando-se as variáveis de forma composta.

A tabela 1 contém os dados relativos ao sexo dos respondentes, totalizando os resultados de forma isolada. Os percentuais demonstram que os homens representam a maioria dos usuários que participaram da pesquisa.

\begin{tabular}{l|c|c} 
Tabela 1 - Sexo & \multicolumn{1}{|c}{} \\
\hline Sexo & Total & Percentual \\
\hline Feminino & 06 & $46,15 \%$ \\
Masculino & 07 & $53,85 \%$ \\
\hline TOTAL & 13 & $100,00 \%$ \\
\hline
\end{tabular}

As tabelas 2 e 3 combinam duas variáveis, sexo e faixa etária, totalizando os resultados agrupados por faixa etária, com os respectivos percentuais.

Pode-se, ainda, inferir pela análise dessas duas tabelas que os usuários do sexo masculino representam a maioria, sendo que a faixa etária de 36 a 40 anos apresenta a maior freqüência para os dois gêneros. No caso dos usuários do sexo masculino, como pode ser observado, a segunda maior freqüência está concentrada na faixa etária de 26 a 30 anos. 
Tabela 2 - Mulheres por Faixa Etária

\begin{tabular}{c|c|c}
\hline Faixa etária & Total & Percentual \\
\hline $26-30$ & 01 & $7,69 \%$ \\
$31-35$ & 01 & $7,69 \%$ \\
$36-40$ & 02 & $15,38 \%$ \\
$41-45$ & 01 & $7,69 \%$ \\
$46-50$ & 01 & $7,69 \%$ \\
\hline TOTAL & 06 & $46,15 \%$ \\
\hline
\end{tabular}

Tabela 3 - Homens por Faixa Etária

\begin{tabular}{c|c|c}
\hline Faixa etária & Total & Percentual \\
\hline $26-30$ & 02 & $15,38 \%$ \\
$36-40$ & 04 & $30,77 \%$ \\
$46-50$ & 01 & $7,69 \%$ \\
\hline TOTAL & 07 & $53,84 \%$ \\
\hline
\end{tabular}

A tabela 4 trabalha com as variáveis cargo e função, agrupando os dados relativos aos servidores que ocupam cargos efetivos com as respectivas funções comissionadas ocupadas por esses servidores.

\begin{tabular}{c|c|c|c} 
Tabela 4 - Cargo e Função \\
\hline Cargo & Função & Total & Percentual \\
\hline Efetivo & CJ & 02 & $15,38 \%$ \\
Efetivo & FC02 & 01 & $7,69 \%$ \\
Efetivo & FC04 & 08 & $61,54 \%$ \\
Efetivo & FC05 & 01 & $7,69 \%$ \\
Sem vínculo & CJ & 01 & $7,69 \%$ \\
\hline TOTAL & - & 13 & $100,00 \%$ \\
\hline
\end{tabular}

Os resultados indicam que a maioria dos usuários entrevistados ocupa cargos efetivos, além disso, todos são ocupantes de função comissionada, sendo que um dos servidores não tem vínculo empregatício com o serviço público.

Quanto ao uso dos subsistemas do SAG, da análise da tabela 5 observa-se que "Envio Eletrônico" e "Índice de Sessão" não são utilizados ou são utilizados raramente pela maioria dos usuários respondentes. Por outro lado, os outros dois subsistemas, "Editor de Documentos" e "Informações Processuais", são muito utilizados. 
Tabela 5 - Freqüência de uso do sistema

\begin{tabular}{l|c|c|c|c}
\hline \multicolumn{1}{c|}{ Sistema } & Diariamente & Semanalmente & Raramente & Não utiliza \\
\hline Editor de Documentos & 07 & - & - & - \\
Envio Eletrônico & - & 01 & 02 & 03 \\
Índice de Sessão & - & - & 02 & 05 \\
Informações Processuais & 06 & 01 & - & - \\
\hline \multicolumn{1}{c|}{ TOTAL } & 07 & 02 & 04 & 08 \\
\hline
\end{tabular}

A tabela 6 demonstra que os usuários não concordam que o "Editor de Documentos" permite uma eficiente formatação dos textos.

Tabela 6 - Ambiente do de formatação de textos do Editor de Documentos O Editor possui um ambiente que permite uma eficiente formatação dos textos?

\begin{tabular}{c|c|c|c}
\hline Concordo & Discordo & Discordo totalmente & Indiferente \\
\hline 01 & 02 & 01 & 03 \\
\hline
\end{tabular}

Segundo a tabela 7, os usuários concordam que a disposição da tela de consulta das informações processuais não prejudica a compreensão das informações.

Tabela 7 - Visualização das informações processuais

\begin{tabular}{c|c}
\hline As informações processuais podem ser visualizadas sem prejudicar a compreensão? \\
\hline Concordo & Discordo \\
\hline 06 & 01 \\
\hline
\end{tabular}




\section{CONCLUSÃO}

Este trabalho foi desenvolvido objetivando-se a elaboração, aplicação, validação e apresentação de um questionário eletrônico para avaliação da usabilidade do Sistema de Automação de Gabinetes do Superior Tribunal de Justiça, sob a ótica do usuário do sistema.

O questionário prévio foi preparado e submetido aos usuários selecionados, ocasião em que foi constatada a necessidade de alguns ajustes para a confecção do questionário definitivo.

Quanto aos resultados, constatou-se que as variáveis pesquisadas nas questões elaboradas corresponderam às questões relativas à escala de maneira satisfatória.

A sugestão para outros trabalhos desta natureza seria direcionar a pesquisa para os servidores da área administrativa para melhor avaliação de todos os subsistemas integrantes do SAG.

Conclui-se que o objetivo do trabalho foi alcançado, ou seja, a elaboração de um instrumento de avaliação da usabilidade do Sistema de Automação de Gabinetes do STJ, sob o ponto de vista do usuário. 


\section{REFERÊNCIAS}

ALBERTÃO, Edmar Sebastião. Sistemas de gestão empresarial; metodologia para avaliação, seleção e implantação. São Paulo: Iglu, 2001. 102p.

BEAL, Adriana. Gestão estratégica da informação; como transformar a informação e a tecnologia da informação em fatores de crescimento e de alto desempenho nas organizações. São Paulo: Atlas, 2004. 137p.

BIO, Sérgio Rodrigues. Sistemas de informação: um enfoque gerencial. São Paulo: Atlas, 1991, 183p.

CYBIS, Walter; BETIOL, Adriana Holtz; FAUST, Richard. Ergonomia e Usabilidade: Conhecimentos, métodos e aplicações.São Paulo: Novatec Editora, 2007. 344p.

FERREIRA, Simone Bacellar Leal; NUNES, Ricardo Rodrigues. e-Usabilidade. Rio de Janeiro: LTC, 2008.

ISO 9126. Software engineering - Product quality - part 1: Quality model. ISO, 2001.

LAUDON, Kenneth C.; LAUDON, Jane Price. Gerenciamento de sistemas de informação. $3^{\mathrm{a}}$ ed. Rio de Janeiro: LTC, 2001. 433p.

O'BRIEN, James A. Sistemas de informação e as decisões gerenciais na era da internet. $2^{\mathrm{a}}$ ed. São Paulo: Saraiva, 2006. 431p.

Regimento Interno do Superior Tribunal de Justiça. Organizado pelo Gabinete do Diretor da Revista. Brasília: STJ, 2008. 220p.

SANTIAGO JÚNIOR, José Renato Sátiro. Gestão do conhecimento; a chave para o sucesso empresarial. São Paulo: Novatec Editora, 2004. 204p.

TURBAN, Efraim; RANIER, R. Kelly; POTTER, Richard E. Administração de tecnologia da informação; teoria e prática. Rio de Janeiro: Elsevier, 2005. 618p. 